\title{
Doing Gender on and off the Pitch: the World of Female Football Players
}

\author{
by John Harris \\ Kent State University \\ Sociological Research Online, Volume 12, Issue 1,
< http://wnw. socresonline.org.uk/12/1/harris.htm/>
doi:10.5153/sro.1367
}

Received: 25 Jan 2006 Accepted: 18 Sep 2006 Published: 31 Jan 2007

\begin{abstract}
The following paper looks at the experiences of female football (soccer) players at a College of Higher Education in the South of England. Association Football occupies a special place in English society where it has traditionally been linked to notions of toughness, manliness and hegemonic masculinity. The last decade has witnessed expedient growth in the number of women playing football and this has led to much debate related to the positioning of the game in contemporary society.
\end{abstract}

Data was collected through an ethnographic approach utilizing observation and semi-structured interviews. Through their very participation in the game the women can be seen to be challenging notions of male hegemony. However their acceptance of the male game as being more important, and their adopting of discourse and ideologies emanating from the male model of the sport, means that they are also colluding in the (re)production of masculine hegemony.

For the women in this study, of central importance to the development of a female footballing identity are issues surrounding sexual orientation within the football world. Women's football in England suffers from an 'image problem' which can and does lead to tension both on and off the pitch. This paper explores how these women make sense of their own involvement in the game and how they negotiate the contested ideological terrains surrounding femininity, masculinity and sexual orientation.

\section{Keywords: Women's Football, Hegemony, Femininity, Masculinity, Sexual Orientation.}

\section{Introduction}

Football is not a woman's game, it's not a pastime for milksops or sissies, it's a man's game. (Trevor Ford - former international football player)

It is people's perceptions, it is like if I go home and say I play for a college team they say girls don't play football. (Patricia - collegiate football player)

1.1 The following paper looks at the experiences of female football (soccer) players at a college of Higher Education in the South of England. Football occupies an exalted place in English culture and has come to assume an important role in relation to the (re)presentation of hegemonic forms of masculinity. Developing his ideas on the work of Gramsci, Connell (1987) was the first to examine the 'naturalizing' of gendered practice in relation to the concept of hegemony. As Bryson (1990: p.181) notes hegemonic masculinity 'revolves around domination and construction of the other as inferior' and it is apparent that in the history of football this 'other' has often been women. Football is also the national sport of England, or as Walvin (1975) suggested, 'the people's game'. It is a world where 'boys become men', a place for the development and promotion of masculinity, and an arena characterised (historically at least) by the almost exclusive maleness of it all (e.g. Hornby, 1992; Morris, 1981; Tomlinson, 1995; Walvin, 1975). Fishwick (1989: p.147) suggested that this does perhaps explain why it became such a popular activity for many males:

The game probably appealed to some precisely because it excluded women and seemed to endorse simple, conservative attitudes to sex roles. All the confusions, complexities doubts and mysteries that might surround dealings with the opposite sex could be avoided in an activity that provided a reassuring link with one's boyhood and youth. 
1.2 Football in English culture is perceived by many to be the embodiment of masculinity. Tomkins (1993) is one of the few to explore the link between football and its (re)presentation as an arena which promotes and celebrates hegemonic masculinity. His research of football texts found that there was very little in the football literature that lent itself towards what one would view as the 'ideal' or traditional masculinity. In fact it was only in the sports pages of the tabloid press that attempts are made to portray football players in this way. Although recent research would attest to the fact that football culture still plays an important role in the (re)production and perpetuation of hegemonic forms of masculinity (Clayton, 2005; Parker, 2001; Whannel, 2002), the modern game also provides many more opportunities for females to become involved in the sport.

1.3 There are now an estimated 30 million plus female players worldwide (Cox and Thompson, 2000) and the game has witnessed expedient growth in England during the last decade (Football Association, 2001). For a brief period, at the start of the century, Fulham Ladies Football Club operated as a professional team. The film Bend it like Beckham, focusing on the experiences of a young English girl of South Asian descent, raised the profile of the game further and presented and promoted images of the sport in other spheres of popular culture (see also, Scraton, Caudwell and Holland, 2005). Yet alongside these developments there continues to be a strong resistance to women's football. Media coverage is still minimal and there is a lack of funding afforded to the sport at all levels. Harris (2005) suggests that the game suffers from an 'image problem', which presents arguably the most significant barrier to the future development of the sport.

1.4 This paper aims to critically examine the ways in which the players themselves understand, and make sense of, their participation in the game. It begins by looking at aspects of the school experiences of the players and examining the way(s) in which gender is (re)constructed and performed in relation to school sport. It assesses the way(s) in which the football players 'do gender' arguing that gender is best conceptualised not as a role but as something that people do (West and Zimmerman, 1991). It then purports that, within the contemporary game, the female football player represents something of a contested ideological terrain. Messner (1988) first applied this descriptor with reference to the female athlete and the rapid development of women's football in the last twenty years makes it an appropriate time to apply and analyse such a descriptor to this particular sport. The study concludes by teasing out some of the key themes to emerge from the players' own experiences through highlighting issues that were deemed most important to the women themselves. Before moving on to discuss specific findings of the primary research I will provide an overview of key methodological considerations to explain the context of, and background to, the study.

\section{Methodology}

2.1 The data for this study was collected over a period of two years and involved extensive field observations coupled with in-depth semi-structured interviews at an institute of Higher Education in the South of England. An interpretive approach was adopted as it was thought that this provided the opportunity for the women to best articulate their own points of view (Sparkes, 2002). The roots of interpretivism can be found in the German intellectual tradition of hermeneutics and the Verstehen tradition in sociology, the phenomenology of Schutz, and critiques of scientism and positivism in the social sciences (Schwandt, 1994). Such an approach promotes the uniqueness of human enquiry, celebrating the permanence and priority of the real world of subjective first person experience. In attempting to see the world from the participants' point of view, the aim is to try to understand how individuals construct social reality. Although this work draws upon the writings from a range of disciplinary backgrounds it does not subscribe exclusively to any one particular school of thought. The 'exhaustion of grand narratives' (Kivisto, 1998: p.139) characterised by the move from macro to micro sociology (Macionis and Plummer, 1997) purports that it is no longer appropriate to make sweeping generalisations about the world we inhabit. Such a viewpoint is in itself not new for Mills (1970) wrote about the increasing fluidity of boundary lines and urged scholars to focus upon the significant issues of their time. Within (post)modern sport few other issues have been as visible or contested as those surrounding gender, yet in the Sports Studies writing many discussions of theory tend to be esoteric. Theories should now be read in narrative terms as 'tales of the field' (Van Maanen, 1988). Given the acknowledged overlap between different approaches an interpretive analysis is deemed to be more inclusive than any other term and points to the features of resemblance amongst various approaches (Sparkes, 1992, 2002). This philosophy is based on an emic perspective and an ideographic approach to the research act.

2.2 Data for this study was collected through field observations undertaken at a range of venues in and around the football world of these women including match fixtures, the student union bar, and various sites on the college campus. Studies of ethnographic research often describe 'sanitised' accounts of how the research was undertaken in an attempt to adhere to the methodological protocol espoused by a traditional/positivistic paradigm. The approach adopted for this study is probably best described as 
'opportunistic' (Reimer, 1977) for we typically use an informal strategy to begin fieldwork and start wherever we can 'slip a foot in the door' (Fetterman, 1991: p.93). The research took place at the institution where I had been awarded a research bursary to undertake what was broadly defined as football related research. No pressure was placed upon me to look at any one particular area and the focus of the study emerged in a truly inductive fashion.

2.3 Following more than a year of observation where I attended matches played by the women, and spoke with many of the players in places such as the student union bar, and a cafeteria on campus, interviews were conducted in an office at the campus where the majority of the women studied. During the two seasons I undertook the research approximately $95 \%$ of the players within the football squad were students within the same department where I was a PhD student. During my first year I had got to know a number of the women and one individual who had come to speak to me seeking advice for her final year dissertation was the first person I interviewed. As each subsequent interview took place some women suggested other members of the squad who they felt I should talk to. The playing squad, for the second season I was undertaking the research, comprised of fifteen women. All of the squad were white and most were between 18 and 21 years of age. This reflected the wider demographic of the larger student body within the faculty, which was predominantly white and largely composed of 18-21 year olds. ${ }^{[1]}$ The football players came from different parts of England and from a range of diverse class backgrounds. Nine interviews were undertaken lasting an average of one and a half hours in duration. Each interview was, with the respondent's permission, recorded on audiotape and transcribed in full. Two of the most established players on the team, including the club captain, became valued 'gatekeepers' in the research and facilitated introductions to members of the squad whom I did not know that well. An ongoing analysis of the research data commenced at an early stage in the study as such concomitant action allows the research design to emerge over time (Hammersley and Atkinson, 1995; Maykut and Morehouse, 1994). Each of the players was also given a pseudonym to ensure anonymity and confidentiality of responses.

2.4 Hargreaves (1994) noted that there have been relatively few ethnographic studies of women's sport in England. More than a decade on and the lived experiences of women in sports such as football are much more visible in the academic literature (e.g. Caudwell, 1999, Harris, 2005; Scraton, Caudwell and Holland, 2005) although there are still many stories to be told. The aim of this paper is to present an authentic account of the football players' experiences utilizing their own words wherever possible. In examining the competing discourses and ideologies, which encompass their world, I aim to explore the tensions centering around masculinity, femininity and sexual orientation as these were themes identified as important by the football players themselves. The study highlights that the women's introduction to, and continued participation in, the game has not come about in an uncontested way. Given the acknowledged importance of early sporting experiences, in relation to future sporting participation, I begin by looking at the (re)creation of gendered identities through sport in schools. This also attempts to tease out some of the key themes underpinning the tensions surrounding masculinity, femininity and sexual orientation that would emerge as central aspects of their college football experiences.

\section{Football in schools: Creating masculine and feminine sporting identities}

3.1 The initial introduction to the game for these players were varied and there was no one single influence that seemed to be the most important across the group. Some had experienced positive family support, some cited the influence of a particular teacher, whilst others had only taken up the sport during their time in Higher Education. As part of learning more about how these women came to play football I asked them to talk about their experiences of the game at school.

\subsection{Scraton (1995: p.125) suggested that school Physical Education (PE) 'fails to provide "meaningful} experiences" for many young adolescent women because it appears at odds with the culture of femininity'. Whereas Physical Education (and particularly the major team sports such as football) is perceived as the embodiment of masculinity, there is no such correlation between female sports involvement and femininity. If anything sports participation (particularly in team games) is still often seen as oppositional to desirable and exalted forms of femininity (Choi, 2000; Cooky and McDonald, 2005; Messner, 2002). The most salient aspects of school PE that are carried over into adult life are the major team games, which in English society are widely seen as synonymous with masculinity, hence becoming problematic for female participants. Participation in football, for the majority of women, was definitely out of the question during their time in school. Many talked of how boys dominated the playground space and refused to let them take part, voicing comments such as 'you can't play, you're a girl' (see Harris 2002). Renold (1997) highlights how the playground has the potential to be a 'gender neutral' space where identities are formed and reformed, destroyed and contested. Yet football's domination of the space, and the exclusion of girls from this, is highlighted through recalling comments from boys such as 'we don't want play with girls' (Rebecca) and 'girls don't play football' (Patricia). This is demonstrative of how in the formative years certain activities are already deemed to be gendered spaces and the male/female dichotomy serves as a 
visible signifier of who can and who can't take part in certain sports. As Renold (1997: p.10) noted the power of football as a specifically male sport is demonstrated by the fact that many girls accepted this exclusion 'coz it's football'.

3.3 Activities that did become popular in schools (and wider society) about the time that these women were in secondary school are often described under the title of the 'aerobics and fitness boom'. Popularised through 'glamorous' actresses, fashion models and the like, such activities became a key part of the move by a number of women back into various forms of physical activity (Choi, 2000; Sports Council, 1993; Tomlinson, 1995). Although one could argue that this is very much a positive aspect, in that a number of people who do not like or are not good at team sports may be provided with an avenue for exercise, others have criticised such activities (e.g. Choi, 2000; Scraton, 1995; Tomlinson, 1995). As Scraton (1995: p.121) suggests:

The message being reinforced in these situations is that young women should not be interested and involved in physical activity in order to develop strength and fitness but should be concerned in enhancing their appearance, in making themselves more 'attractive', particularly to the opposite sex.

3.4 Female athletes are often defined primarily in relation to their perceived sexual attractiveness and the coverage afforded to them within the media is often dependent on 'looks' as opposed to their sporting success (Harris and Clayton, 2002). Influenced by these images, and the depicting of women within popular magazines, considerable pressure is placed upon females to conform to an 'ideal' body type (Choi, 2000). The style of PE kits is cited as a significant factor in putting a number of girls off sport as they become more and more conscious of their body shape. As Patricia recalled:

I hated what we had to wear like those gym knickers, like we had to walk to the gym and I didn't have a very nice figure then, not much of one now (laughs).

3.5 Patricia describes herself as being very conscious of her body, and was convinced that such experiences are powerful shapers in the future sports participation of a number of females. At this age many adolescents (both boys and girls) are very sensitive to their body shape and the process of physical maturation. Such issues are on the whole more problematic for girls given the social pressures linked to 'desirable femininity'. To appeal to the 'male gaze' is an integral part of this ideal, and to demonstrate 'desirable femininity', generally does not encompass participation (and certainly not competence) in sport. The subject of the 'male gaze' was a theme brought up by many of the women themselves in the interviews. This does not mean that the women were constantly trying to achieve a stereotyped image of feminine perfection. How and why this was important to them needs to be located and understood in the context of 'doing' or 'performing' gender as female football players. This in itself is an ongoing performance that is continually in progress. The socio-cultural positioning of the sport, and its exalted status in many male dominated spheres of English society, helps contextualise their experiences and provides an insight into the environment within which these stories can be read.

3.6 Patricia suggested that a number of girls are socialised into 'hating football' - 'It seemed to be a boy's sport and girls couldn't play it.' It appears that there is a sense of conflict, due to the fact that the football players are not exposed to ( $\mathrm{m}$ )any images of athletic women from a very early age. As Lorna noted 'I just didn't see any women play sport, you know, not on telly or anything. I only saw men play proper sport'. It was apparent that for many of the players 'athlete' and 'woman' just did not seem to fit together in their taken for granted assumptions of the world. When I asked them to name any football players they admired all of the women only mentioned male players. When pressed to discuss female athletes who they remember from their childhood many of the women struggled to come up with a single figure. This lack of visible female athletes in the media was significant and so in some ways placed an increased importance on the role of the female Physical Education teacher as a 'visible' sporting figure.

3.7 Scraton (1988: p.282) notes that whilst most teachers agreed that girls had the capability to play football, they were against the sport as it was perceived to be an 'undesirable' female activity:

I have yet to see an elegant women footballer. Maybe I'm just prejudiced but they just look horrible. I just don't like seeing women playing football. If they did, I would definitely want to modify it.

Football! - I have a personal thing about this. I've been to a women's football match, and there's nothing sorer to my feminine eyes than a big bust and a big behind and the attracted crowd and spectators ... I won't let the girls play because it is very, very unfeminine - I associate that with a man. I feel very strongly that I will never let the girls play soccer. 
3.8 Female PE is considered to be less important than male PE, which forms an important part of the male identity and the development of hegemonic forms of masculinity (Humberstone, 2002). For girls and women participation in a number of physical activities may be considered as undesirable (Choi, 2000). In addition to this, there is also the stereotypical portrayal of the female PE teacher as being a lesbian. This particular theme emerged on a number of different occasions during the interviews, as highlighted by the following comments:

A lot of people didn't like her, 'cos they thought she was a lesbian (Tracey)

Yeah and the classic rumour - 'oh, she is a lesbian' (Sonia)

3.9 When I asked Tracey why people had this impression of this particular woman, she replied 'cos she probably was (laughs), she was like - really masculine'. Both Sonia and Tracey's interpretations are based to an extent on the fact that the women in question 'had short hair', 'never wore any make-up' (Sonia) and 'were scruffy looking' (Tracey). Such views highlight the problems faced by many female PE teachers, who themselves may still be expected to conform to traditionally prescribed notions of femininity. This presumed association between being a female PE teacher and being a lesbian presents potential problems for many (heterosexual) women students of the subject, where a number of gender management strategies are adopted to ensure that they are recognised as heterosexual and feminine (Flintoff, 1994).

3.10 This association between sport and sexual orientation was something that the women themselves would encounter on numerous occasions during their time playing football in college. It was far and away the single most cited theme to emerge in the primary research and represented for many the most important issue to talk about during the interviews. It is important to note here that discussing issues related to sexual orientation were always topics of conversation initiated by the players themselves. The semi-structured interview format I followed for each interview did not include any questions related to sexual orientation. If the interviewee did not bring up the subject then I did not introduce it in the interview. All players interviewed signed an agreement of informed consent which highlighted that their participation was voluntary, offered to end the interview at any time, and stated that they could refuse to answer any question. Where the players' introduced the subject it was usually with specific reference to either the image of the game or as a way of explaining tensions surrounding their own identity as a football player. ${ }^{[2]}$

\section{Doing gender in collegiate football}

4.1 In understanding more about their positioning as football players at the collegiate level, I became interested in how the women 'do gender' within and around the football world. West and Zimmerman (1991) suggest that gender should not be viewed as a role but as something people do. This highlights the role of the individual in actively engaging in constructing gender relations. It is important to acknowledge that gender is an ongoing process constructed both by the individual and by society. Viewed this way, gender is a set of socially constructed relationships that are produced and reproduced through people's actions. It is important to note here that dominant masculinities and femininities are not absolutely forced upon individuals as many people willingly conduct themselves in ways, which configure them as masculine or feminine, and some enjoy this polarity of gender (Connell, 2002).

4.2 Butler's $(1990,1993)$ research has been particularly influential in framing the work of a number of scholars including those in Sports Studies. Butler (1990) suggests that gender is not the expression of what we are but is something that we 'perform'. For Butler $(1990,1993)$ gender is not 'naturally' ascribed but is a changing social construct that demonstrates fluidity and multiplicity. Individuals actively negotiate this performance and do this within a particular socio-cultural context. Yet this is not necessarily an active choice for social learning perpetuates gender norms and prioritises 'appropriate' behavior, which in turn reinforces certain cultural norms. Butler's $(1990,1993)$ work is important in terms of discrediting essentialist ideas about gender. It must also be noted that with reference to doing or performing gender there are numerous roles we can adopt and that we may move between different roles dependent on the situation or context (see also, Ussher, 1997).

4.3 On discussing the image of the game all of the women were quick to point out that the game suffered from a poor image and that their own participation was normally associated with having their sexual orientation questioned. This constituted the most visible and consistent theme to emerge in the whole of the research highlighting the tensions inherent within their very participation in the game. It also impacted significantly upon how many of the women 'did gender' in the spaces in and around their football world. The football players talked openly about the perception of the sport and all seemed aware of the common image of the game. As Tracey suggests 'that's the thing though with women's football, you got that kind of ... like people are really shocked when I say I play football'. As what would be described as a very feminine looking woman (certainly in terms of the images we are presented with), Tracey does not fit the stereotypical image of a female football player, which according to Patricia is 'man like' or 'butch' (see also, Caudwell, 1999, 
2002; Mennesson and Clement, 2003). Many of the players felt quite strongly about having to constantly state their (hetero)sexual identity and recalled comments that participants from other sports had made. As Donna recalled:

Well there was something that I heard last year, which I wasn't too happy about. I think it was Imogen actually. You know Imogen (I nod), she was saying something to one of the lads, oh I think she was pretty drunk at the time, something about oh you know girls playing football must be gay. When I heard that I was like, I couldn't believe it but I suppose some people also think that.

4.4 Patricia suggested that the common perception was that 'most ladies that play football are gay, like a lot of people think this team at college is lesbian'. This association continues to be a central component of the everyday discourse that surrounds the game (see also, Caudwell, 1999; Harris, 2005). Following the 2005 European Championships in England many internet discussion pages focused upon one member of the England team based solely upon her looks and appearance. Yet discourse centering around the sexual orientation of the player was just as visible and became the central discussion point.

4.5 Issues surrounding the lesbian label and the image of the game were by far the strongest and most visible themes to emerge in the primary research and two quite contrasting images of women's football were visible within the course of the study. The college team presented themselves as a predominantly heterosexual site where the women strived to develop a distinct identity as football players. This contrasted markedly to a nearby club (Wanderers) that presented a very different idioculture of women's football. Here, although it was not an exclusively gay club, sexual preference was deemed to be a central component of the club's identity. Caudwell (2002) has described such an environment as a 'dykescape'. Hargreaves (2000) has also highlighted how sport provides a unique space for lesbian women to be together (see also, Broad, 2001; Caudwell, 2002). This presents an interesting site for the exploration of contested identities within women's football. Of all the football players at the college, only one woman also played for Wanderers. Mary was introduced to the club as she was dating one of the other players who was also the secretary of the club. During the two years I undertook this research Mary was the only (out) lesbian on the college team. Some of the other players in the team refused to go and play for Wanderers highlighting sexual orientation as being a key factor in their decisions:

Oh yeah I know they are (lesbians), cos Mary plays for them, and Mary's gay. She used to go out with one of the secretaries there, and they split up and now they are not letting Mary play in the first team because of that (laughs). (Donna)

Wanderers, they wanted me to play for them, and apparently the whole team are lesbians, so I said no. I said yeah, then my mate said do you know they are all lesbians? So that did put a thing on it. (Hannah)

4.6 Although there has been a great deal of valuable research looking at the problems faced by lesbian athletes in the sports world, what has often been overlooked in the research on women's football are the experiences of heterosexual players. Hargreaves (2004) has highlighted the importance of the work of a number of lesbian feminists to the subject of sport and sexuality. Although not referring specifically to the experiences of heterosexual football players in her analysis it may well be that they are a group 'whose voices and ideas have been suppressed' (Hargreaves, 2004: p.201). For the women who form the focus of this study having to constantly state and reaffirm their own sexual orientation became a tiresome task and was something that caused many of them more angst and irritation than anything else. ${ }^{[3]}$

\section{The female football player as contested ideological terrain}

5.1 It is evident that in many ways the female football player in England has become something of a contested ideological terrain. Messner (1988) used this term when describing the experiences of the female athlete, highlighting how women had been given numerous sporting opportunities yet their very participation results in their femininity and sexual orientation being scrutinised. Although female athletes have made significant progress in a variety of sporting contexts, there is an added complexity to taking part in a sport so central to notions of hegemonic masculinity. Many nations have a dominant football code that provides an important reference point for notions of manliness and, by association, wider masculine ideals (see Giulianotti, 1999; MacCambridge, 2005; Nauright and Chandler, 1996). Sabo and Panepinto's (1990: p.115) description of football (gridiron) in the USA could just as easily be applied to association football in England where they note that:

Football's historical prominence in sports media and folk culture has sustained a hegemonic model of masculinity that prioritises competitiveness, athleticism, success (winning), aggression, violence, superiority to women, and respect for the compliance with male 
authority.

5.2 As Messner (1987) noted sport became the 'last bastion' of traditional masculine values and the football literature is replete with writing which (re)present the game as being a fiercely masculine world (e.g. Clayton, 2005; Hornby, 1992; Parker, 2001; Morris, 1981). The link between football and perceived notions of masculinity and toughness surfaced on numerous occasions during the course of the work. Rebecca suggested that '... men are less afraid of jumping and dropping to the floor. I would never do that', and Jane noted that 'if you hit them down some say sorry. The blokes would not do that'.

5.3 Although the development of women's football (soccer) in the United States of America is often cited as a model of how the game can develop further in England, these arguments do not take into account the massive differences in terms of the social, cultural and historical locatedness of the sport in the two countries. It is noticeable that even in the USA, where the national female team has significantly raised the profile of the game, there continues to be difficulties in developing the game further to incorporate a fully professional league system (Longman, 2000; Roberts, 2005; Southall, Nagel and LeGrande, 2005).

5.4 Trying to become 'accepted' as football players represented an important area for many of the women and they talked openly about the problems they had faced in trying to move the game forward. According to Patricia, trying to develop the game has been an uphill struggle:

Well basically, when we started no one took us seriously... it was OK we set up a friendly match but there was no, we had to use the boys kit, no special treatment, and when we went up to the astro-turf we had to pay for it and the boys would get it free, and they would have particular times maybe because it was a new sport at the time and they could not fit it in, but at the time it was frustrating when you are trying to get something off the ground.

5.5 What was interesting from speaking to a number of the women was that although they recognized how and where discrimination was occurring they often accepted that the needs of some of the male teams came first. The women's subordinate role within football at the college was visibly demonstrated by the allocation of pitches for matches. When asked to talk about their experiences of playing the game at the college many of the players highlighted the pitch as a visible demonstrator of their locatedness within the football hierarchy:

Oh, we always get the worst pitch, the slow pitch, like 'you are over there, see you later (laughs). A lot of people do not know that we have a women's team as they haven't seen us play, cos you can see the blokes play on a Wednesday afternoon, you can't really miss them, but us you can. (Patricia)

When we first started it was a struggle, and we do have trouble finding referees, and if we do play up here we never get put on the flat pitch. (Jane)

5.6 What was interesting was that many of the women accepted that the men's first team should have the best pitch as demonstrated by Hannah's comment that 'the first team boys come first'. Where their real grievances lay was when the men's fourth team were given a better pitch and more support. In talking about the game none of the women mentioned a female football player from the higher levels as not one could recall the name of any international player. When asked which players they admired all referred to male players from the Premier League and in describing their participation at the college many used their male counterparts as reference point in explaining key issues. Donna referred to the fact that the women seemed to 'bunch up a lot' during the game and how this differed to the men 'because lads have been playing football since they were little'. Rebecca also highlighted the way in which many females had been steered away from certain activities suggesting that 'Cos man's football, they've been brought up playing it at school, where we've been tried to persuade not to play it until recently'.

5.7 The women's very participation in the sport of football does in some way challenge male hegemony. Yet by highlighting that the higher ranked men's teams in the college should have first call on facilities and all other support shows that in some ways the women were reproducing male hegemony (see also, Harris 2001, 2004). By holding the male model of the sport up as the model to adhere to, and adopting much of the discourse associated with the male game, the women can be seen to be actively colluding in the (re)production of masculine hegemony. Also by describing male football as 'real' football and locating their own activity as something different from this the football players were (re)positioning the women's game in a different way. Discussions pertaining to how best to 'position' the sport continues and there is not yet any consensus as to how the future development of the game can best be served (see Hargreaves, 1994, Harris 2006, Longman, 2000). 
distinct identity. Many of the football players talked proudly of the fact that they often had more people watching them than the men's first team. They are also aware that they are developing their own identity as the women's football team. As Lorna noted:

When we go out people recognise us as the women's football team. I mean, they know who we are, as we sometimes all dress up in a particular way or whatever. Yesterday for example, a couple of lads who I didn't even know came up to me and asked how we got on in the match.

5.9 For Lorna, being recognised as 'women footballers in our own right' is a very important part in the development of the game at the collegiate level. Establishing a distinct identity as football players appeared to be a key factor underpinning many of the decisions the players made. Sonia believed that the fact that many of the team were 'keen on football generally' helped to present an acceptable image which helped to justify their participation. Demonstrating some knowledge of the game helped to 'legitimise' their involvement in the sport and was used by a number of the male players of incorporating the women into the wider football culture at the institution. Yet what must also be noted here is that this was also a result of the ways in which a number of the women visibly and vociferously emphasised their femininity demonstrating that this was not compromised by their involvement in the game (see also Harris 2004).

5.10 The central role of promoting a particularly 'feminine' image was something that many of the women touched upon in the interviews. As Cockerill and Hardy (1989: p.150) suggested:

The demonstration of strength, speed and endurance in specific athletic settings may be detrimental to a girls feminine image. On the other hand, where fitness is related to weight control, to developing a good figure, and to general well being i.e. looking good and feeling good, then the feminine image may well be enhanced.

$5.11 \mathrm{It}$ is noticeable that the most well known female athletes of recent times tend to be those who take part in individual sports. The inexpedient amount of media coverage afforded to the tennis player Anna Kournikova provides a visible exemplar of how a 'desirable' femininity is exalted within the English media (Harris and Clayton, 2002). Irrespective of their perceived 'looks' or (non)conformity to a particular feminine ideal, almost all of the women recalled stories of how their physicality was analysed and assessed through their very participation in football. The norm that depicts women as experts in the management of appearance is embedded in the larger Western conception of femininity (Miller and Penz, 1991). Through their very participation in the game, and by promoting a particular image, the women could be viewed as demanding the right to be recognized as both 'feminine' and as footballers.

5.12 It is hardly surprising that given the continued association between football and masculinity, that these women experience conflict between being female and being a football player. Much other research on the game has also highlighted this aspect (e.g. Caudwell, 1999, 2002; Cox and Thompson, 2000; George, 2005; Kolnes, 1995; Mennesson and Clement, 2003) and the sources of conflict that exist between being female and being an athlete have also been investigated in sports such as boxing (Halbert, 1997) and golf (Crosset, 1995). Halbert (1997) suggests that the female pugilists have to adopt a strategy of 'identity management'. The football players that I talked with also seemed to adopt such an approach. For many heterosexual women it seemed to be a way of dealing with having their sexual orientation questioned. Linked to this, the majority of women strongly resisted the term 'feminist'. To them, the term was implicitly linked with a perceived sexual orientation though their resistance was probably more of a reaction to a social stereotype rather than any particular ideology.

\section{Concluding remarks}

6.1 The popular perception of women's football is changing (albeit slowly). The number of registered players in England has risen markedly (Football Association, 2001), and the players I spoke to generally agreed that the game is taken a little more seriously than it had been previously. However, it is important that we do not over estimate this, for in many quarters women's football is still viewed as something of 'an amusing eccentricity' (Williams and Woodhouse, 1991). The Football Association's (2001) aim of having a women's professional league in place is still to be met. Although many have cited the fact that Fulham Ladies FC became the first fully professional team in Europe, this was a short lived venture and was the result of a rich benefactor rather than any particular strategic or development initiative. The continued lack of serious media coverage, the continuous questioning of players' sexual orientation, and the continued popularisation of the male game all need to be located in any measured analysis (Harris 2005). Some ten years ago the Head of football's world governing body (FIFA) suggested that the future of football was feminine. In an English context such a statement seems a little quixotic and there continues to be a long way to go before the game can match up to much of the rhetoric espoused by administrators of the game. 
6.2 Playing football can represent both a liberating and empowering experience for many women (Caudwell, 1999; Cox and Thompson, 2000; George, 2005; Mennesson and Clement, 2003; Longman, 2000; Scraton, Caudwell and Holland, 2005). The locatedness of the game, as it relates to dominant and exalted forms of masculinity, has a significant effect upon how female football players 'do gender' in England. Two quotations presented at the start of the paper were comments made some forty years apart yet are demonstrative of how despite significant progress some ideas and ideologies remain the same. The progress made by the women whose words are presented in this study highlight how individuals can challenge and change aspects of gendered identities. Yet it is also important to acknowledge that the experience presented are from the members of one particular idioculture and any findings, whilst highly suggestive, cannot be generalised and applied to the game as a whole. Showing how the football players 'do gender' provides insights into how femininity and masculinity are performed, (re)produced and understood. In some ways the women have been able to legitimize their involvement in the game and taken their participation to the stage where the term woman football player was no longer perceived and mocked as an oxymoron.

\section{Notes}

${ }^{1}$ Few studies have considered race and ethnicity in women's football. The film Bend it like Beckham provides an excellent insight into some of the factors impacting upon the football experiences of a young South Asian girl in the South of England. Scraton, Caudwell and Holland (2005) also offer an interesting account of race and ethnicity in their recent work on the game.

2 This reflects my understanding of, and commitment to, an interpretive research perspective that aims to provide an authentic account of the experiences of the group. I try to present the stories of the football players by highlighting the issues deemed most important by them. Such an approach is inductive and differs markedly from the (traditional) deductive approach that shaped much of the early research in Sports Studies. Sparkes (2002) provides an insightful and informative overview of some of the key factors underpinning interpretive research.

3 Interestingly there was no acknowledgement, or discussion, of bisexual identities within these interviews. The players all talked about sexual orientation as being something specific and did not consider 'sexual fluidity and multiplicity' (Broad, 2001: p.195).

\section{References}

BROAD, K. (2001) 'The gendered unapologetic: Queer resistance in women's sport', Sociology of Sport Journal, Vol. 18, No. 2, pp.181-204.

BRYSON, L. (1990) 'Challenges to male hegemony in sport', in M. Messner and D. Sabo (editors) Sport, Men and the Gender Order. Champaign, IL: Human Kinetics.

BUTLER, J. (1990) Gender Trouble: Feminism and the Subversion of Identity . London: Routledge.

BUTLER, J. (1993) Bodies that Matter. London: Routledge.

CAUDWELL, J. (1999) 'Women's football in the United Kingdom: theorizing gender and unpacking the butch lesbian image', Journal of Sport and Social Issues, Vol. 23, No. 4, pp.390-402.

CAUDWELL, J. (2002) 'Women's experiences of sexuality within football contexts: A particular and located footballing epistemology', Football Studies, Vol. 5, No. 1, pp.24-45.

CHOI, P. (2000) Femininity and the Physically Active Woman . London: Routledge.

CLAYTON, B. (2005) Tales from the pitch: An ethnography of male collegiate football masculinities.

Unpublished PhD thesis, Brunel University.

COCKERILL, S. and HARDY, C. (1989) 'The concept of femininity and its implications for physical education', The British Journal of Physical Education, Vol. 18, No. 4, pp.149-151.

CONNELL, R. (1987) Gender and Power. Stanford: Stanford University Press.

CONNELL, R. (2002) Gender. Cambridge: Polity.

COOKY, C. and McDONALD, M. (2005) 'If you let me play: Young girls' insider-other narratives of sport', Sociology of Sport Journal, Vol. 22, No. 2, pp.158-177. 
COX, B. and THOMPSON, S. (2000) 'Multiple bodies: Sportswomen, soccer and sexuality', International Review for the Sociology of Sport, Vol. 35, No. 1, pp.5-20.

CROSSET, T. (1995) Outsiders in the Clubhouse: The World of Women's Professional Golf . Albany, NY: SUNY Press.

FETTERMAN, D. (1991) 'A walk through the wilderness: Learning to find your way', in W. Shaffir and R. Stebbins (editors) Experiencing Fieldwork: An Inside View of Qualitative Research . London: Sage.

FISHWICK, N. (1989) English Football and Society: 1910-1950. Manchester: Manchester University Press.

FLINTOFF, A. (1994) One of the boys? An ethnographic study of gender relations, co-education and initial teacher education in physical education. Unpublished PhD thesis, Open University.

FOOTBALL ASSOCIATION (2001) The Football Development Strategy 2001-2006. London: Football Association.

GEORGE, M. (2005) 'Making sense of muscle: The body experiences of collegiate women athletes', Sociological Inquiry, Vol. 75, No. 3, pp.317-345.

GIULIANOTTI, R. (1999) Football: A Sociology of the Global Game . Cambridge: Polity.

HALBERT, C. (1997) 'Tough enough and woman enough: Stereotypes, discrimination, and impression management among women professional boxers', Journal of Sport and Social Issues, Vol. 21, No. 1, pp.736.

HAMMERSLEY, M. and ATKINSON, P. (1995) Ethnography: Principles in Practice (2 ${ }^{\text {nd }}$ ed). London: Routledge.

HARGREAVES, J. (1994) Sporting Females. London: Routledge.

HARGREAVES, J. (2000) Heroines of Sport. London: Routledge.

HARGREAVES, J. (2004) 'Querying sport feminism: Personal or political?', in R. Giulianotti (editor) Sport and Modern Social Theorists. Basingstoke: Palgrave Macmillan.

HARRIS, J. (2001) 'Playing the man's game: Sites of resistance and incorporation in women's football', World Leisure, Vol. 43, No. 4 pp.22-29.

HARRIS, J. (2002) 'No you can't play you're a girl: Some primary school recollections of female football players', The Bulletin of Physical Education, Vol. 38, No. 3, pp.161-178.

HARRIS, J. (2004) 'Still a man's game? Women footballers, personal experience and tabloid myth' in S. Wagg (editor) British Football and Social Exclusion. London: Routledge.

HARRIS, J. (2005) 'The image problem in women's football', Journal of Sport and Social Issues , Vol. 29, No. 2, pp.184-197.

HARRIS, J. (2006) 'Ahead of the game?', Recreation: The Journal of the Institute of Sport and Recreation Management, May, pp.32-34.

HARRIS, J. and CLAYTON, B. (2002) 'Femininity, masculinity, physicality and the English tabloid press: The case of Anna Kournikova' International Review for the Sociology of Sport , Vol. 37, No. 3/4, pp.397413.

HORNBY, N. (1992) Fever Pitch. London: Victor Gollanz.

HUMBERSTONE, B. (2002) 'Femininity, masculinity and difference: What's wrong with a sarong?', in A. Laker (editor) The Sociology of Sport and Physical Education . London: Routledge.

KIVISTO, P. (1998) Key Ideas in Sociology. Thousand Oaks, CA: Pine Forge Press.

KOLNES, L. (1995) 'Heterosexuality as an organizing principle in women's sport', International Review for the Sociology of Sport, Vol. 30, No. 1, pp.61-76.

LONGMAN, J. (2000) The Girls of Summer: The US Women's Soccer Team and How it Changed the World. New York: Harper Collins. 
MACCAMBRIDGE, M. (2005) America's Game: The Epic Story of How Pro Football Captured a Nation . New York: Anchor Books.

MACIONIS, J. and PLUMMER, K. (1997) Sociology: A Global Introduction. New Jersey: Prentice Hall.

MAYKUT, P. and MOREHOUSE, R. (1994) Beginning Qualitative Research: A Philosophical and Practical Guide. London: Falmer Press.

MENNESSON, C. and CLEMENT, J. (2003) 'Homosociability and homosexuality: The case of soccer played by women', International Review for the Sociology of Sport , Vol. 38, No. 3, pp.311-330.

MESSNER, M. (1987) 'The life of a man's seasons: male identity in the life course of the Jock', in M. Kimmel (editor) Changing Men: New Directions in Research on Men and Masculinity . Beverly Hills, CA: Sage.

MESSNER, M. (1988) 'Sport and male domination: The female athlete as contested ideological terrain', Sociology of Sport Journal , Vol. 5, pp.197-211.

MESSNER, M. (2002) Taking the Field: Women, Men and Sports. Minneapolis, MN: University of Minnesota Press.

MILLER, L. and PENZ, O. (1991) 'Talking bodies: female bodybuilders colonize a male preserve', Quest, Vol. 43, No. 2, pp.148-163.

MILLS, C.W. (1970) The Sociological Imagination. Harmondsworth: Penguin (First published in 1959).

MORRIS, D. (1981) The Soccer Tribe. London: Jonathan Cape.

NAURIGHT, J. and CHANDLER, T. (1996) (editors) Making Men: Rugby and Masculine Identity . London: Frank Cass.

PARKER, A. (2001) 'Soccer, servitude and subcultural identity: Football traineeship and masculine construction', Soccer and Society, Vol. 2, No. 1, pp.59-80.

RENOLD, E. (1997) 'All they've got on their brains is football: Sport, masculinity and the gendered practices of playground relations', Sport, Education and Society, Vol. 2, No. 1, pp.5-23.

REIMER, J. (1977) 'Varieties of opportunistic research', Urban Life, Vol.5, pp.467-477.

ROBERTS, S. (2005) A Necessary Spectacle: Billie Jean King, Bobby Riggs, and the Tennis Match that Leveled the Game. New York: Crown.

SABO, D. and PANEPINTO, J. (1990) 'Football ritual and the social reproduction of masculinity', in M. Messner and D. Sabo (editors) Sport, Men and the Gender Order . Champaign, IL: Human Kinetics.

SCHWANDT, S. (1994) 'Constructivist, interpretivist approaches to human inquiry', in N. Denzin and Y. Lincoln (editors) Handbook of Qualitative Research. Newbury Park, CA: Sage.

SCRATON, S. (1988) Shaping up to womanhood: A study of the relationship between gender and girls' physical education in a city based local education authority. Unpublished PhD thesis, Open University.

SCRATON, S. (1995) 'Boys muscle in where angels fear to tread - girls' subcultures and physical activities', in C. Critcher, P. Bramham and A. Tomlinson (editors) Sociology of Leisure: A Reader . London: E \& FN Spon.

SCRATON, S., CAUDWELL, J. and HOLLAND, S. (2005) 'Bend it like Patel: Centring race, ethnicity and gender in feminist analysis of women's football in England', International Review for the Sociology of Sport, Vol. 40, No. 1, pp.71-88.

SOUTHALL, R., NAGEL, M. and LeGRANDE, D. (2005) 'Build it and they will come? The Women's United Soccer Association: A collision of exchange theory and strategic philanthropy', Sport Marketing Quarterly, Vol. 14, pp.158-167.

SPARKES, A. (1992) 'The paradigms debate: An extended review and a celebration of difference', in A. Sparkes (editor) Research in Physical Education and Sport: Exploring Alternative Visions . Lewes: Falmer Press.

SPARKES, A. (2002) Telling Tales in Sport and Physical Activity. Champaign, IL: Human Kinetics. 
TOMKINS, J. (1993) 'The football discourse: The generation and control of the male and female body and its impact on the football world', in C. Brackenridge (editor) Body Matters: Leisure Images and Lifestyles .

Eastbourne: Leisure Studies Association.

TOMLINSON, A. (1995) 'Ideologies of physicality, masculinity and femininity: Comments on Roy of the Rovers and the women's fitness boom', in A. Tomlinson (editor) Gender, Sport and Leisure: Continuities and Challenges. Eastbourne: Leisure Studies Association.

USSHER, J. (1997) Fantasies of Femininity: Reframing the Boundaries of Sex . London: Penguin Books.

VAN MAANEN, J. (1988) Tales of the Field: On Writing Ethnography. Chicago: University of Chicago Press.

WALVIN, J. (1975) The People's Game. London: Allen Lane.

WEST, C. and ZIMMERMAN, D. (1991) 'Doing gender', in J. Lorber and S. Farrell (editors) The Social Construction of Gender. Newbury Park, CA: Sage.

WHANNEL, G. (2002) 'From pig's bladders to Ferraris: Media discourses of masculinity and morality in obituaries of Stanley Matthews', Culture, Sport, Society, Vol. 5, No. 3, pp.73-94.

WILLIAMS, J. and WOODHOUSE, J. (1991) 'Can play will play? Women and football in Britain' in J. Williams and S. Wagg (editors) British Football and Social Change. Leicester: Leicester University Press. 